\title{
Rapid Detection of Severe Fever with Thrombocytopenia Syndrome Virus via Colloidal Gold Immunochromatography Assay
}

\author{
Jia-Ying Zuo, ${ }^{\dagger}$ Yong-Jun Jiao, $^{\dagger}$ Jin Zhu, $^{\S}$ and Shou-Nian Ding ${ }^{*}{ }^{\dagger}$ \\ University, Nanjing 211189, China \\ ${ }^{\ddagger}$ Jiangsu Provincial Center for Disease Control and Prevention, Nanjing 210009, China \\ ${ }^{\S}$ Huadong Medical Institute of Biotechniques, Nanjing 210002, China
}

$\dagger$ Jiangsu Province Hi-Tech Key Laboratory for Bio-Medical Research, School of Chemistry and Chemical Engineering, Southeast

Supporting Information

ABSTRACT: To develop the point-of-care testing method to facilitate the clinical detection of severe fever with thrombocytopenia syndrome virus (SFTSV), colloidal gold paper-based lateral flow immunochromatography test strips (LFITSs) have been fabricated for the rapid detection for the first time. The $\mathrm{pH}$ value and the amount of monoclonal antibody to prepare colloidal gold nanoparticle-labeled monoclonal antibody bioconjugates were optimized. In addition, $0.4 \%$ bovine serum albumin was considered to be the best concentration for blocking nitrocellulose membranes. Under optimal conditions, the limit of detection for SFTSV was as low as $1 \mathrm{ng} / \mathrm{mL}$ depending on a visual line. Meanwhile, the entire detection process required no more than $10 \mathrm{~min}$ with a volume of only $50 \mu \mathrm{L}$ of the analyte solution. Moreover, paper-based LFITSs were evaluated in real samples of human serum of patients with satisfactory results. In addition, all strips were of high stability and specificity. In the light of advantages such as simple, portable, rapid, and low cost, the developed LFITSs will extensively come into service, especially in remote areas.

\section{INTRODUCTION}

Severe fever with thrombocytopenia syndrome (SFTS) caused by the newly discovered bunyavirus is of high mortality rate in the eastern and central regions of China in recent years. ${ }^{1-5}$ As reported, ${ }^{6-8}$ SFTS virus (SFTSV) genome is a single negative chain RNA virus, which consists of three fragments ( $\mathrm{L}, \mathrm{M}$, and $S)$. The $\mathrm{L}$ fragment encodes RNA polymerase. The M fragment encodes envelope glycoprotein ( $\mathrm{Gn}$ and $\mathrm{Gc}$ ), ${ }^{9,10}$ which has hemagglutination activity and plays a key role in the fusion of virus and host cells. Most notably, apart from nonstructural protein NSs, the S fragment encodes nucleocapsid proteins at the same time, which are closely related to virus replication. ${ }^{11}$ According to the reports, ${ }^{1,12}$ SFTSV infection contributes to sudden fever, respiratory or gastrointestinal symptoms, decreased white blood cell count, bleeding, and multiple organ failure. To date, not only have the disease virus been separated successfully, but also its sequences have been elucidated. ${ }^{13}$ On the other hand, research studies (e.g., etiology, epidemiology, clinical medicine, etc.) have been carried out in recent years. ${ }^{13}$ Whereas diagnosis of SFTSV demand a robust and complicated laboratory system making use of virus isolation, virus nucleic acid detection, and immunological detection commonly. For instance, quantitative ELISA detection of SFTSV had been reported, which could detect the antigen concentration of $1 \mathrm{ng} / \mathrm{mL}$. Unfortunately, its applications were bounded as a result of fussy washing steps and incubation procedures. ${ }^{14,15}$ The lack of universal test methods for SFTSV infection is a growing awkward situation. To date, there is no paper-based strip to rapidly detect SFTSV on the basis of colloidal gold nanoparticles (Au NPs), where inexpensive and portable tests can be utilized by unskilled individuals for determination.

On the other hand, extensive attention has been paid to immunoassay in various fields, such as food safety detection, ${ }^{16-18}$ environmental monitoring, ${ }^{19,20}$ drug detection, ${ }^{21}$ medical testing, ${ }^{22-24}$ and so on. Although a series of specific, sensitive, and quantitative immunoassays have sprung up and been employed, such as fluorescence, ${ }^{25}$ electrochemical luminescence, ${ }^{26}$ and electrochemistry, ${ }^{27}$ their shortcomings cannot be easily overlooked, which are intricate and timeconsuming. Thus, simple, fast, and sensitive new-style immunochromatography technology ${ }^{28}$ seems to be more in line with personal daily requirements, which is an indispensable component of point-of-care testing (POCT) ${ }^{29}$ and only depend on capillary force to make the fluid migrate. As for immunochromatography technology, great attempts have been made toward signal reporters all the time. So far, to achieve the purpose of quantitative detection of the analyte, a number of signal reporters were taken into account, such as latex particles, ${ }^{30-32}$ magnetic nanoparticles, ${ }^{33-35}$ upconverting

Received: September 12, 2018

Accepted: October 31, 2018

Published: November 13, 2018 
luminescence, ${ }^{36,37}$ fluorescent quantum dots (QDs), ${ }^{38-40}$ and organic fluorescent dyes. ${ }^{41}$ Among them, QDs and colloidal Au NPs were considered as bright participants in paper-based lateral flow immunochromatography test strips (LFITSs). In contrast with QDs endowed with high fluorescence quantum yield and tunable emission wavelength, ${ }^{42} \mathrm{Au}$ NPs were also concerned on account of the advantages of excellent stability, eye reading results, surface modification, shape, and sizedependent optical properties. ${ }^{43}$ Furthermore, Au NPs had incomparable biocompatibility ${ }^{44}$ and a simpler process of synthesis compared with QDs containing deleterious heavy metal ions. ${ }^{45,46}$ Therefore, paper-based LFITSs based on Au NPs are a powerful tool for direct, rapid, and low-cost POCT via visible lines, and this technique does not require any sophisticated specialized instruments and complex analysis. ${ }^{47,48}$ As markers, paper-based LFITSs based on Au NPs were first applied to detect human chorionic gonadotropin (HCG). ${ }^{49}$ Afterward, paper-based LFITSs based on Au NPs were widely applied in many fields.

In this article, by combining the merits of paper-based LFITSs and the singular properties of Au NPs, we presented a rapid detection method of novel bunyavirus SFTSV for the first time. The design and response principle of paper-based LFITSs are demonstrated in Scheme 1. The developed strips

Scheme 1. Schematic Illustration of Operation Principle of Paper-Based LFITSs

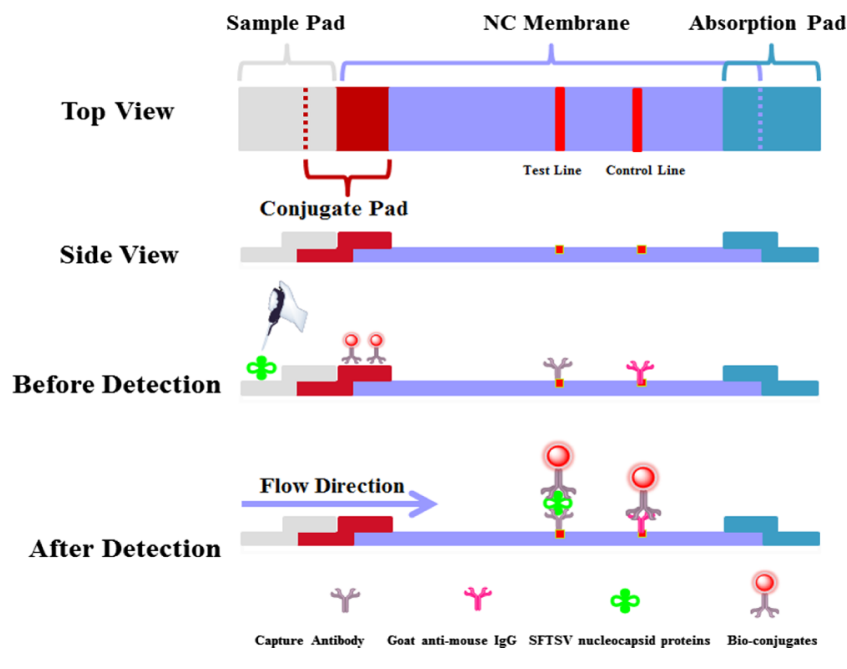

were very simple and cost-effective for SFTSV detection, and the whole detection process can be fulfilled easily within 10 min with satisfactory results, revealing that LFITSs based on $\mathrm{Au}$ NPs have a great potential to be used as the POCT for SFTSV detection. Taking into account the advantage of practical value to monitoring SFTSV, the developed paperbased strips have a great prospect, especially in routine applications.

\section{RESULTS AND DISCUSSION}

2.1. Principle of the Method. Paper-based LFITSs were operated on the basis of sandwich-type immunoreaction. Scheme 1 illustrated the test principle of LFITSs, which was consistent with the previous reports. ${ }^{50,51}$ During the test, SFTSV nucleocapsid proteins primarily formed conjugates with the Au NPs-monoclonal antibodies (mAbs) and then reacted with the test $(\mathrm{T})$ line antibodies on the nitrocellulose
(NC) membrane to form double antibodies sandwich complex before fixed and accumulated visible red lines to the naked eye. The unreacted bioconjugates continued to move by chromatography and incorporated into goat antimouse IgG at the control (C) line, resulting in the visible red line. Thus, a red $\mathrm{T}$ line representing the test of SFTSV virus was positive, whereas a $\mathrm{T}$ line that did not display red was considered to be negative. Last but not least, red $\mathrm{C}$ lines indicated that paperbased LFITS were effective. If $\mathrm{C}$ lines did not display red, no matter what the result of $\mathrm{T}$ lines were, it would indicate that LFITSs were invalid and the test results were meaningless (Scheme 2A). The presence of target proteins was judged by

Scheme 2. (A) Straightforward Signal Readout of PaperBased LFITSs and (B) Photos of Paper-Based LFITSs Assembled in Cassettes in the Absence (Left) and Presence (Right) of SFTSV Nucleocapsid Proteins

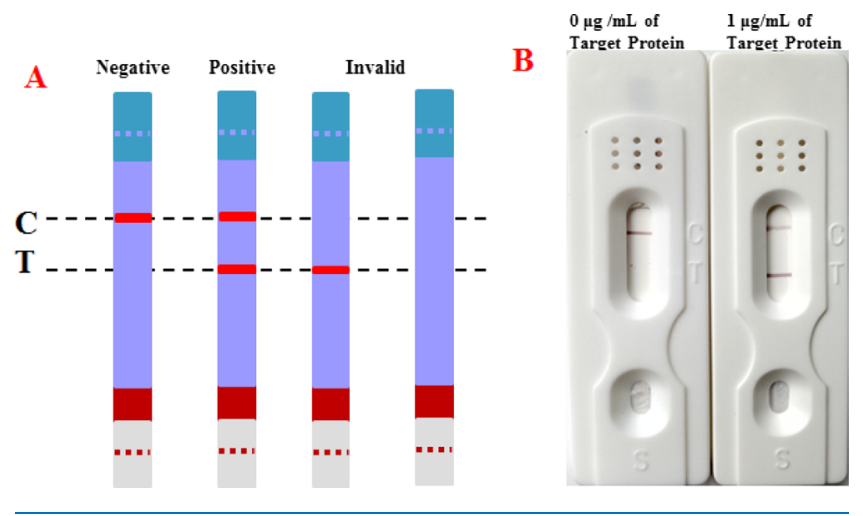

the specific color tracer of colloidal gold particles. The test results were read directly by visual method within $10 \mathrm{~min}$. As shown in Scheme 2B, only the C line showed red color in the absence of SFTSV nucleocapsid proteins, indicating that the background signal was very weak and the test result was valid. On the other hand, paper-based LFITSs assembled in cassettes displayed two red lines to detect $1 \mu \mathrm{g} / \mathrm{mL}$ of SFTSV nucleocapsid proteins.

2.2. Characterization of Au NPs. Figure $1 \mathrm{~A}$ showed maximum visible absorption wavelength of Au NPs, which was at $521 \mathrm{~nm}$ in conformity with the literature, ${ }^{52}$ and a narrow peak shape also showed that the particles had homogeneous particle. The morphology and dispersion of Au NPs were characterized by typical transmission electron microscopy (TEM). As showed in Figure 1B, it can be observed that Au NPs had a good uniformity and dispersion, and the inset showed that the average particle size was $20 \mathrm{~nm}$.

$\mathrm{T}$ lines were characterized by scanning electron microscopy (SEM) to visualize the morphology under different concentrations of SFTSV nucleocapsid protein antigen. In Figure 1C, $\mathrm{Au}$ NPs were hardly observed in the $\mathrm{T}$ line, when SFTSV nucleocapsid proteins were absent $(0 \mathrm{ng} / \mathrm{mL})$. A weak background signal indicated that the nonspecific adsorption was low. Nevertheless, Figure 1D showed that it was obvious to observe $\mathrm{Au} \mathrm{NPs,} \mathrm{explaining} \mathrm{that} \mathrm{a} \mathrm{large} \mathrm{number} \mathrm{of}$ bioconjugates were captured because of $1 \mu \mathrm{g} / \mathrm{mL}$ of SFTSV nucleocapsid proteins. Therefore, the presence of SFTSV nucleocapsid proteins can be distinguished by the naked eye.

2.3. Optimization of the LFITSs. The performance of $\mathrm{Au}$ NPs on paper-based LFITSs would be affected by certain parameters, such as the properties of $\mathrm{Au}$ NPs-mAbs under different $\mathrm{pHs}$, the mixture ratio between $\mathrm{Au}$ NPs and 

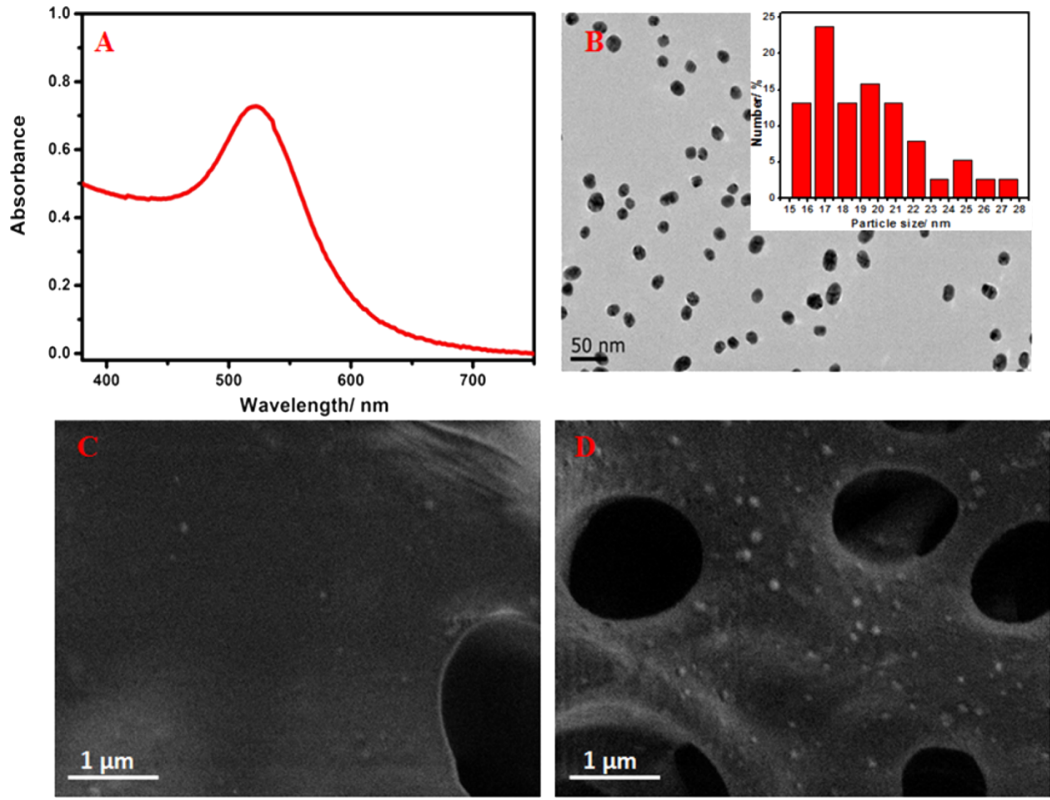

Figure 1. (A) UV-vis spectra of Au NPs. (B) TEM image of Au NPs. (C) SEM image of the test line of paper-based LFITS detecting (C) without and (D) with $1 \mu \mathrm{g} / \mathrm{mL}$ SFTSV nucleocapsid proteins; the white spots represented Au NPs.

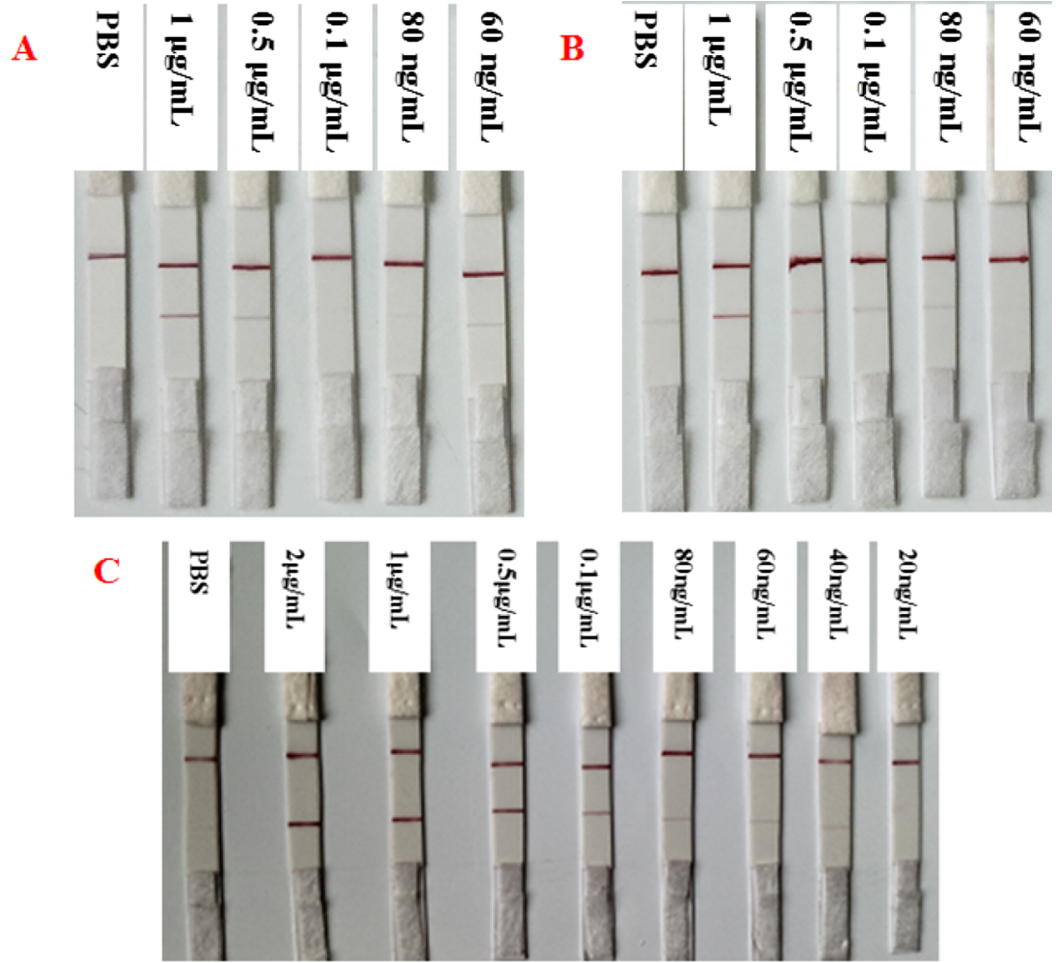

Figure 2. Sensitivity of paper-based LFITSs based on different types of membranes for the detection of SFTSV nucleocapsid proteins in PBS solutions: (A) Sartorius CN140, (B) Vivid 170, and (C) Millipore 135.

antibodies, different types of NC membranes, and the concentration of bovine serum albumin (BSA) solution applied to the NC membranes. According to the literature, ${ }^{53,54}$ when the $\mathrm{pH}$ gets close to the isoelectric point of antibodies, ionic and hydrophobic interactions bring about the stronger physical adsorption of antibodies onto the surface of Au NPs, which are negatively charged in the alkaline environment. The effect of mAbs labeled to the Au NPs under a series of $\mathrm{pH}$ (6.0, 7.0, 8.0, 9.0, and 10.0) was first investigated. Figure S1A displayed changes in color under different $\mathrm{pHs}$, where the response to PBS was determined in parallel as the control. Under the destructive effect of high concentration of salt, the color of $\mathrm{Au}$ $\mathrm{NPs}-\mathrm{mAbs}$ solution under $\mathrm{pH}$ values less than 7.0 altered from red to blue because of its accumulation. On the other hand, when the $\mathrm{pH}$ values were more than 7.0, there was no change in the color of the solution. Hence, the optimal $\mathrm{pH}$ value was ascertained at 8.0 , which was considered as a full stabilization of bioconjugates solution. 


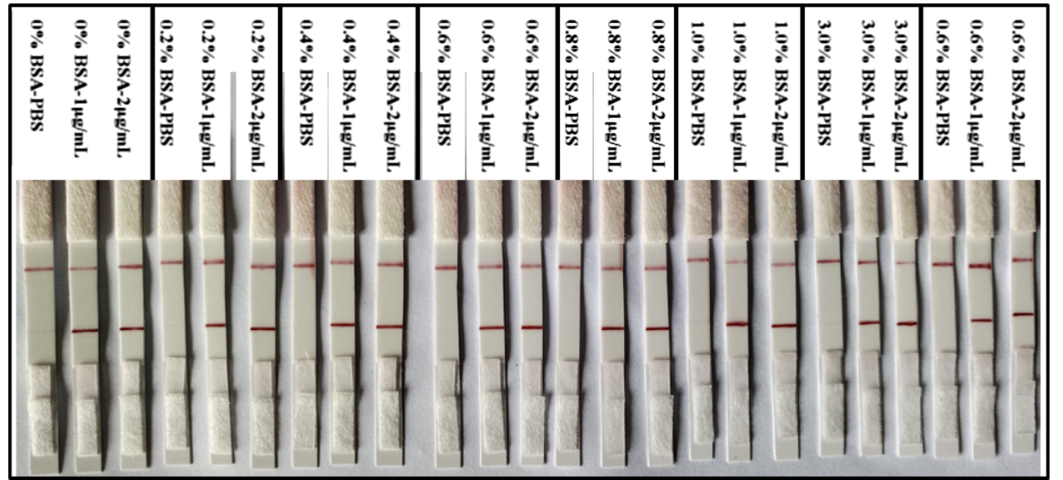

Figure 3. Photos of paper-based LFITSs blocked by different concentrations of BSA solution to detect SFTSV nucleocapsid proteins of 1 and $2 \mu \mathrm{g} /$ $\mathrm{mL}$, respectively.

Next, to increase the sensitivity of the detection, mAbs levels labeled $\mathrm{Au}$ NPs were optimized by the salt tolerance. A series of antibody solutions $(0.4,0.8,1.2,1.6,2.0,2.4,3,4,5$, and 6 $\mu \mathrm{g}$ ) were added into $\mathrm{Au} \mathrm{NP}$ solutions under the optimal $\mathrm{pH}$ value. In Figure S1B, the high concentration of salt directly induced accumulation, which could be observed by a color shift from red to blue at $0.4 \mu \mathrm{g}$ of mAbs. However, Au NP solution containing $0.8 \mu \mathrm{g}$ of mAbs could remain red after reacting with $\mathrm{NaCl}$ solution. Furthermore, according to previous reports, ${ }^{60}$ beneficial for a better stabilization of $\mathrm{Au}$ NPs, the concentration of selected mAbs should be more than the above mAb concentration. Consequently, $1.2 \mu \mathrm{g}$ of MAbs for the conjugation was taken into consideration.

In addition, employed as important solid supports of test strips, different types of NC membranes influenced the sensitivity of the tests. In this study, three frequently used NC membranes, including Sartorius CN140, Vivid 170, Millipore 135, were investigated. The results indicated that the velocities of liquid under the same experimental conditions were not very different. As shown in Figure $2 \mathrm{~A}-\mathrm{C}, \mathrm{T}$ and $\mathrm{C}$ lines remained remarkable with low background. To detect SFTSV nucleocapsid proteins, the detection limit based on Sartorius CN140 and Vivid 170 was $0.5 \mu \mathrm{g} / \mathrm{mL}$ and $80 \mathrm{ng} / \mathrm{mL}$, respectively. Notably, Millipore 135 had a better performance as low as $40 \mathrm{ng} / \mathrm{mL}$. Hence, it was chosen the best suitable membrane to assemble lateral strips.

The block of NC membranes was another crucial factor affecting the performance of paper-based LFITSs. Many researchers have emphasized the benefits of BSA for membrane blocking. As previously reported, ${ }^{55-58}$ treated with a certain concentration of BSA, NC membranes have the effects of slowing down the speed of flow, increasing signal, abating nonspecific binding, and increasing stability. Different concentrations of BSA solution $(0,0.2,0.4,0.6,0.8,1,3$, and $5 \%)$ were applied to block NC membranes of LFITSs, which were used to detect the antigen of 1 and $2 \mu \mathrm{g} / \mathrm{mL}$. In the course of the experiment, PBS was detected as the control. Figure 3 displayed $\mathrm{T}$ lines of all LFITSs that turned red. Furthermore, chromatography of the solution suffered from severe flow resistance because of high concentrations of the blocking buffer. As a result, the flow rate was too slow to make $\mathrm{T}$ and $\mathrm{C}$ lines of paper-based LFITSs take at least $30 \mathrm{~min}$ to produce color. On the basis of the experimental results, $0.4 \%$ BSA was employed for the following experiments.

2.4. Specificity and Stability of Paper-Based LFITSs. To prevent the false-positive phenomenon from cross reaction and detect the presence of SFTSV quickly and accurately, it is of great importance to assess the specificity of paper-based LFITSs. Here, five different antigens were studied: HCG, AFP, CEA, CA125, and SFTSV antigens. As shown in Figure 4, a

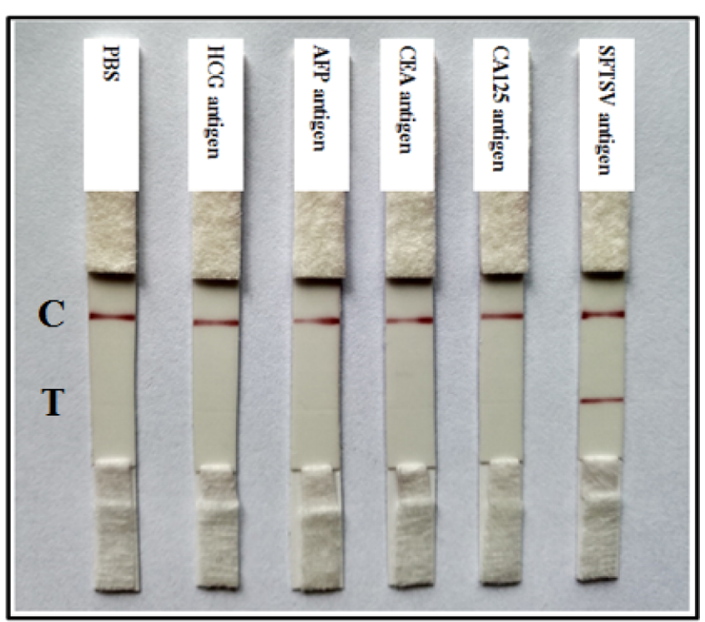

Figure 4. Specificity of paper-based LFITSs. From left to right: blank control, HCG antigen, AFP antigen, CEA antigen, CA125 antigen, and SFTSV antigen. All concentrations were $1 \mu \mathrm{g} / \mathrm{mL}$.

standard solution of $1 \mu \mathrm{g} / \mathrm{mL}$ for each antigen was applied to LFITSs and PBS was served as the control. There was no significant change in the color intensity of $T$ lines except SFTSV antigens. These results stated clearly that paper-based LFITSs were specific for the detection of SFTSV nucleocapsid proteins. For other antigens, there was no cross reactivity even though their concentrations were high.

To further evaluate the stability and reproducibility, paperbased LFITSs were applied to detect SFTSV nucleocapsid proteins via using a standard solution $(0,1$, and $2 \mu \mathrm{g} / \mathrm{mL})$ because of their importance to the application of the product. All paper-based LFITSs were divided into three groups and stored at room temperature (RT) for a period (1,2, and 3 weeks). The results in Table $S 1$ revealed no differences in the intensity of $\mathrm{T}$ lines after incubation at different times by the naked eye. Consistent results were obtained for other concentrations. Each concentration was detected for ten times. In addition, the strips could remain functional under storage conditions within 6 months at RT because of the inexistence of false positive and weak signals. The above results showed that the developed paper-based strips have a good stability and detection performance. 

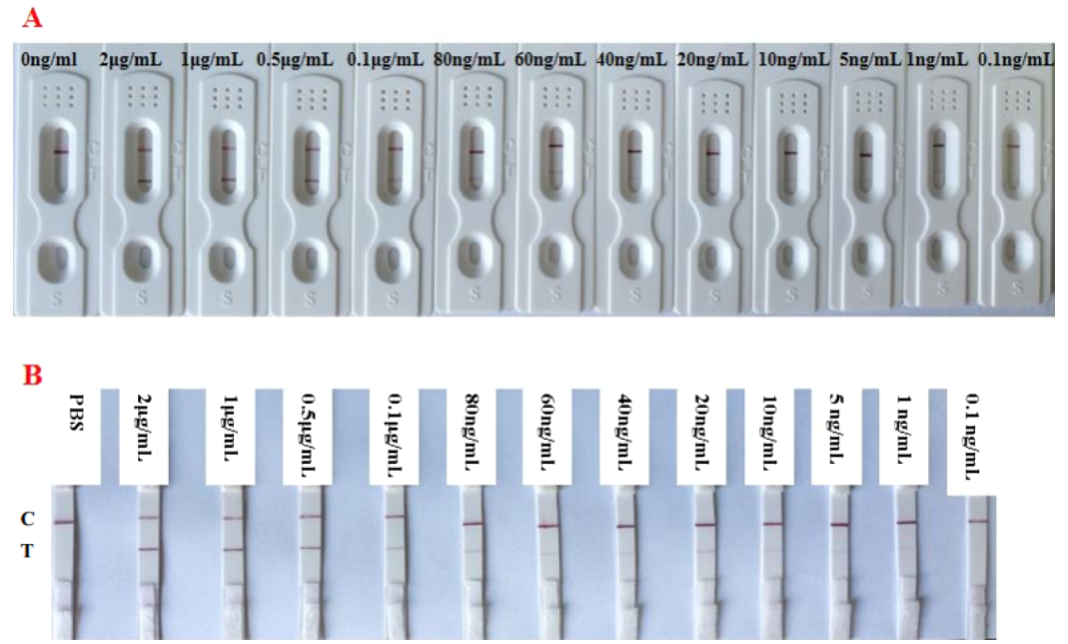

Figure 5. Paper-based LFITSs based on Au NPs for the detection of SFTSV nucleocapsid proteins in PBS solutions (A) in cassettes and (B) outside.

\subsection{Analytical Performance of Paper-Based LFITSs.}

The purpose of the study is to establish a rapid method for the detection of SFTSV by the naked eye. To evaluate the practicability of LFITSs, $50 \mu \mathrm{L}$ of serials of antigen standards $(2,1,0.5,0.1 \mu \mathrm{g} / \mathrm{mL} ; 80,60,40,20,10,1,0.1,0 \mathrm{ng} / \mathrm{mL})$ in PBS buffer ( $\mathrm{pH} 7.4,10 \mathrm{mM})$ were first detected by paperbased LFITSs with each concentration being confirmed in triplicate. After $10 \mathrm{~min}$, as shown in Figure 5A,B, red C lines have proved the validity of the test results. From 0.5 to $2 \mu \mathrm{g} /$ $\mathrm{mL}, \mathrm{T}$ lines were so obvious that we could immediately give a yes/no answer. Among the whole process, the color of $\mathrm{T}$ lines showed a downward trend on account of gradually reduced SFTSV nucleocapsid proteins. In addition, the color was hard to be distinguished under low concentrations. Hence, the detection limit for detecting SFTSV nucleocapsid proteins was $1 \mathrm{ng} / \mathrm{mL}$, and $1 \mu \mathrm{g} / \mathrm{mL}$ was deemed as visualized optimal antigen concentration. In comparison with ELISA kits, the minimum antigen concentrations detected by strips were similar. This fast detection strips were superior to complex ELISA detection method. The rapid detection of SFTSV with high sensitivity has a great prospect for POCT in daily life.

2.6. Analysis of SFTSV in Human Serum by PaperBased LFITSs. To evaluate the practicability for daily application, paper-based LFITSs were also applied to detect six positive serums of patients infected with SFTSV, where normal human serum was assessed as the control. Assay results are listed in Table 1, which were identical with the polymerase

Table 1. Analysis of SFTSV in Human Serum by PaperBased LFITSs ${ }^{a}$

$\begin{array}{ccccccccc}\text { sample } & \text { control } & 1 & 2 & 3 & 4 & 5 & 6 & \\ \text { test results } & - & + & + & + & + & + & + & \text { PCR method } \\ & - & + & + & + & + & + & + & \text { our method } \\ { }^{a} \text { Note: (-) negative result, } & (+) & \text { positive result. }\end{array}$

chain reaction (PCR) method. Also, photos of real-sample analysis (Figure S2) were obvious to the presented results. All results indicated that our developed LFITSs would be helpful in the daily application with accurate results.

\section{CONCLUSIONS}

To sum up, we have designed rapid paper-based LFITSs based on colloidal gold to detect SFTSV. By using the specific binding between antigen and antibody and the capillary action, the proposed strips have a quick, sensitive, and high selective response to SFTSV nucleocapsid proteins. In addition, the whole analysis can be completed within $10 \mathrm{~min}$ without complex analysis, professional personnel, or expensive equipment. Also, the diagnosis of disease in outdoors and remote areas can also be achieved. In comparison with the previously reported SFTSV ELISA kit, this is the first use of a strip as the sensing platform to detect SFTSV with satisfactory results. The developed method could open up a new possibility for POCT to be widely used in daily life.

\section{MATERIALS AND METHODS}

4.1. Materials and Chemicals. SFTSV nucleocapsid proteins and SFTSV mAbs were provided from Jiangsu Center for Disease Control and Prevention (simple preparation process of antibody is shown in the Supporting Information). Goat antimouse IgG was obtained from Shanghai JieYi Biotechnology Co. Ltd. (Shanghai, China). Serums of patients infected with SFTSV and normal human serums were obtained from Jiangsu Province Hospital. Sample pads, conjugate pads (Ahlstrom 8964), NC membranes (Sartorius CN140, Vivid 170, Millipore 135), absorbent pads, and polyvinyl chloride (PVC) baseboards were supplied by Shanghai JieYi Biotechnology Co. Ltd. (Shanghai, China). Other chemicals are shown in the Supporting Information.

4.2. Instruments. All photos of Au NPs and paper-based LFITSs were taken by a telephone digital camera. Data of serum detection using the PCR method were provided by Jiangsu Province Hospital. In addition, other instruments are shown in the Supporting Information.

4.3. Synthesis of Colloidal Au NPs. The preparation of Au NPs with a diameter of $\sim 20 \mathrm{~nm}$ was carried out according to the reported methods with appropriate modifications. ${ }^{30,59,60}$ The detailed synthesis procedures are presented in the Supporting Information. The size of Au NPs was determined by TEM.

4.4. Preparation of Colloidal Au NP-Labeled mAbs Bioconjugates (Au NP-mAbs). According to previous 
literature studies, ${ }^{61,62}$ prior to experiments, the optimal $\mathrm{pH}$ value and mAbs were ascertained, which were pivotal factors affecting the stability of bioconjugates. The $\mathrm{pH}$ of the solution was adjusted by adding $\mathrm{K}_{2} \mathrm{CO}_{3}$. Briefly, a series of different volumes of $0.1 \mathrm{M} \mathrm{K}_{2} \mathrm{CO}_{3}$ were added to the centrifuge tubes containing $200 \mu \mathrm{L}$ of Au NPs. Subsequently, $4 \mu \mathrm{g}$ of mAbs was added into above mixtures and incubated for $10 \mathrm{~min}$ at RT. Then, $45 \mu \mathrm{L}$ of $10 \% \mathrm{NaCl}$ was added to each tube before being mixed uniformly and placed statically for another $2 \mathrm{~h}$. Finally, changes in the color of solutions were directly observed. Similarly, the least amount of mAbs to stabilize $\mathrm{Au}$ NPs solution was determined by varying the amounts of antibodies in the reaction system.

Under optimal conditions, $\mathrm{Au} \mathrm{NPs}-\mathrm{mAbs}$ bioconjugates were prepared as previously reported. ${ }^{1}$ First, $1.2 \mu \mathrm{g}$ of mAbs was added into Au NPs solution, whose $\mathrm{pH}$ was adjusted to 8 under gentle mixing uniformly. After being stirred slightly for another $30 \mathrm{~min}$ at $\mathrm{RT}$, the final solution was mixed with $25 \mu \mathrm{L}$ of $5 \%(\mathrm{w} / \mathrm{v})$ BSA and stirred for another $30 \mathrm{~min}$ for blocking. Then, the products were collected by centrifuging at $1500 \mathrm{rpm}$ for $20 \mathrm{~min}$ to remove large-particle impurity, followed by centrifuging at $15000 \mathrm{rpm}$ for another $20 \mathrm{~min}$. Finally, the obtained products were redispersed in $250 \mu \mathrm{L}$ of $10 \mathrm{mM}$ PBS ( $\mathrm{pH}$ 7.4) containing 5\% sucrose and 1\% BSA for further use.

4.5. Development of LFITSs. A schematic diagram of paper-based LFITSs is presented in Scheme S1. The assembly of the strip was described previously. ${ }^{28,63,64}$ A paper-based LFITS was composed of four sections, including a sample pad $(10 \times 4 \mathrm{~mm})$, a conjugate pad $(8 \times 4 \mathrm{~mm})$, an NC membrane $(20 \times 4 \mathrm{~mm})$ and an absorbent pad $(10 \times 4 \mathrm{~mm})$. Sample pads were used for dropping SFTSV nucleocapsid proteins, whereas conjugate pads were applied to load bioconjugates. Using a double-headed marker pen (SJ001, Shenzhen stationery store) equipped with an extremely small nib (SJ002, $1.97 \times 34 \mathrm{~mm}$, Shenzhen stationery store), the test line and the control line of $\mathrm{NC}$ membranes were prepared by dispensing $2.5 \mathrm{mg} / \mathrm{mL}$ of SFTSV $\mathrm{mAbs}$ and $2.5 \mathrm{mg} / \mathrm{mL}$ of goat antimouse $\mathrm{IgG}$, respectively. The interval between two lines was $5 \mathrm{~mm}$. NC membranes were processed with the treatment solution, which was made up of PBS (10 mM, pH 7.4) containing $1 \%(\mathrm{w} / \mathrm{v})$ BSA before being blocked and dried at $37{ }^{\circ} \mathrm{C}$ for $10 \mathrm{~min}$. All parts were attached to a PVC backing card. Before assembly, the pretreatments of some elements are presented in the Supporting Information. Finally, paper-based LFITSs, which were cut into a $4 \mathrm{~mm}$ width using a scissors, were stored in a sealed bag at $4{ }^{\circ} \mathrm{C}$ until use. The developed paper-based strips could be easily fabricated in batch. In the process of the experiment, an NC membrane can produce 60 devices simultaneously at a cost of US \$ 0.07 each.

4.6. Test Procedures. When SFTSV nucleocapsid protein standard solution $(50 \mu \mathrm{L})$ was added onto the sample pad of paper-based LFITS, it transferred toward the absorbent pad under the action of the capillary force. The presence of target proteins was judged by the specific color tracer of Au NPs. The test results were visible to the naked eye within $10 \mathrm{~min}$.

\section{ASSOCIATED CONTENT}

\section{S Supporting Information}

The Supporting Information is available free of charge on the ACS Publications website at DOI: 10.1021/acsomega.8b02366.
Materials and chemicals, instruments, synthesis of colloidal Au NPs, production of SFTSV mAbs, pretreatment of LFITSs, and optimization of Au NPs-mAbs bioconjugates; stability and reproducibility of LFITSs; and photos of real-sample analysis by paper-based LFITSs (PDF)

\section{AUTHOR INFORMATION}

\section{Corresponding Author}

*E-mail: snding@seu.edu.cn. Fax: (+86) 25-52090621.

ORCID

Shou-Nian Ding: 0000-0003-3086-2333

Notes

The authors declare no competing financial interest.

\section{ACKNOWLEDGMENTS}

This work was supported by the National Natural Science Foundation of China (21535003, 21575022, and 31570926), the Key Research \& Development Plan of Jiangsu Province (BE2018617), Jiangsu Provincial Medical Talent Project (ZDRCA2016031), and Qing Lan Project.

\section{REFERENCES}

(1) Yu, X.-J.; Liang, M.-F.; Zhang, S.-Y.; Liu, Y.; Li, J.-D.; Sun, Y.-L.; Zhang, L.; Zhang, Q.-F.; Popov, V. L.; Li, C.; Qu, J.; Li, Q.; Zhang, Y.P.; Hai, R.; Wu, W.; Wang, Q.; Zhan, F.-X.; Wang, X.-J.; Kan, B.; Wang, S.-W.; et al. Fever with Thrombocytopenia Associated with a Novel Bunyavirus in China. N. Engl. J. Med. 2011, 364, 1523-1532.

(2) Li, D. A highly pathogenic new bunyavirus emerged in China. Emerging Microbes Infect. 2013, 2, No. e1.

(3) Kim, K.-H.; Yi, J.; Kim, G.; Choi, S. J.; Jun, K. I.; Kim, N.-H.; Choe, P. G.; Kim, N.-J.; Lee, J.-K.; Oh, M.-d. Severe Fever with Thrombocytopenia Syndrome, South Korea, 2012. Emerging Infect. Dis. 2013, 19, 1892-1894.

(4) Kurihara, S.; Satoh, A.; Yu, F.; Hayasaka, D.; Shimojima, M.; Tashiro, M.; Saijo, T.; Takazono, T.; Imamura, Y.; Miyazaki, T.; Tsukamoto, M.; Yanagihara, K.; Mukae, H.; Saijo, M.; Morita, K.; Kohno, S.; Izumikawa, K. The world first two cases of severe fever with thrombocytopenia syndrome: An epidemiological study in Nagasaki, Japan. J. Infect. Chemother. 2016, 22, 461-465.

(5) Zhan, J.; Wang, Q.; Cheng, J.; Hu, B.; Li, J.; Zhan, F.; Song, Y.; Guo, D. Current status of severe fever with thrombocytopenia syndrome in China. Virol. Sin. 2017, 32, 51-62.

(6) Lei, X.-Y.; Liu, M.-M.; Yu, X.-J. Severe fever with thrombocytopenia syndrome and its pathogen SFTSV. Microbes Infect. 2015, 17, 149-154.

(7) Wang, X.; Li, B.; Guo, Y.; Shen, S.; Zhao, L.; Zhang, P.; Sun, Y.; Sui, S.-F.; Deng, F.; Lou, Z. Molecular basis for the formation of ribonucleoprotein complex of Crimean-Congo hemorrhagic fever virus. J. Struct. Biol. 2016, 196, 455-465.

(8) Plegge, T.; Hofmann-Winkler, H.; Spiegel, M.; Pöhlmann, S. Evidence that Processing of the Severe Fever with Thrombocytopenia Syndrome Virus Gn/Gc Polyprotein Is Critical for Viral Infectivity and Requires an Internal Gc Signal Peptide. PLoS One 2016, 11, No. e0166013.

(9) Guardado-Calvo, P.; Rey, F. A. Advances in Virus Research; Kielian, M., Mettenleiter, T. C., Roossinck, M. J., Eds.; Academic Press, 2017; pp 83-118.

(10) Wu, Y.; Zhu, Y.; Gao, F.; Jiao, Y.; Oladejo, B. O.; Chai, Y.; Bi, Y.; Lu, S.; Dong, M.; Zhang, C.; Huang, G.; Wong, G.; Li, N.; Zhang, Y.; Li, Y.; Feng, W.-h.; Shi, Y.; Liang, M.; Zhang, R.; Qi, J.; et al. Structures of phlebovirus glycoprotein $\mathrm{Gn}$ and identification of a neutralizing antibody epitope. Proc. Natl. Acad. Sci. U.S.A. 2017, 114, E7564-E7573.

(11) Zhou, H.; Sun, Y.; Wang, Y.; Liu, M.; Liu, C.; Wang, W.; Liu, X.; Li, L.; Deng, F.; Wang, H.; Guo, Y.; Lou, Z. The nucleoprotein of 
severe fever with thrombocytopenia syndrome virus processes a stable hexameric ring to facilitate RNA encapsidation. Protein Cell 2013, 4, $445-455$.

(12) Zhang, X.; Liu, Y.; Zhao, L.; Li, B.; Yu, H.; Wen, H.; Yu, X.-J. An emerging hemorrhagic fever in China caused by a novel bunyavirus SFTSV. Sci. China: Life Sci. 2013, 56, 697-700.

(13) Zhang, W.; Zeng, X.; Zhang, L.; Peng, H.; Jiao, Y.; Zeng, J.; Treutlein, H. R. Computational identification of epitopes in the glycoproteins of novel bunyavirus (SFTS virus) recognized by a human monoclonal antibody (MAb 4-5). J. Comput.-Aided Mol. Des. 2013, 27, 539-550.

(14) Wei, J.; Li, S.; Dong, J.-H.; Tian, H.; Chowell, G.; Tian, H.-Y.; Lv, W.; Han, Z.-Q.; Xu, B.; Yu, P.-B.; Wang, J.-J. The first human infection with severe fever with thrombocytopenia syndrome virus in Shaanxi Province, China. Int. J. Infect. Dis. 2015, 35, 37-39.

(15) Yu, F.; Du, Y.; Huang, X.; Ma, H.; Xu, B.; Adungo, F.; Hayasaka, D.; Buerano, C. C.; Morita, K. Application of recombinant severe fever with thrombocytopenia syndrome virus nucleocapsid protein for the detection of SFTSV-specific human IgG and IgM antibodies by indirect ELISA. Virol. J. 2015, 12, 117.

(16) Wang, Z.; Guo, L.; Liu, L.; Kuang, H.; Xu, C. Colloidal goldbased immunochromatographic strip assay for the rapid detection of three natural estrogens in milk. Food Chem. 2018, 259, 122-129.

(17) Tominaga, T. Rapid detection of Klebsiella pneumoniae, Klebsiella oxytoca, Raoultella ornithinolytica and other related bacteria in food by lateral-flow test strip immunoassays. J. Microbiol. Methods 2018, 147, 43-49.

(18) Ma, L.; Nilghaz, A.; Choi, J. R.; Liu, X.; Lu, X. Rapid detection of clenbuterol in milk using microfluidic paper-based ELISA. Food Chem. 2018, 246, 437-441.

(19) Liu, Y.; Wu, A.; Hu, J.; Lin, M.; Wen, M.; Zhang, X.; Xu, C.; Hu, X.; Zhong, J.; Jiao, L.; Xie, Y.; Zhang, C.; Yu, X.; Liang, Y.; Liu, X. Detection of 3-phenoxybenzoic acid in river water with a colloidal gold-based lateral flow immunoassay. Anal. Biochem. 2015, 483, 7-11.

(20) Barceló, D.; Oubiña, A.; Salau, J. S.; Perez, S. Determination of PAHs in river water samples by ELISA. Anal. Chim. Acta 1998, 376, $49-53$.

(21) Frankfurt, O. S.; Krishan, A. Enzyme-linked immunosorbent assay (ELISA) for the specific detection of apoptotic cells and its application to rapid drug screening. J. Immunol. Methods 2001, 253, 133-144.

(22) Fang, C.-C.; Chou, C.-C.; Yang, Y.-Q.; Wei-Kai, T.; Wang, Y.T.; Chan, Y.-H. Multiplexed Detection of Tumor Markers with Multicolor Polymer Dot-Based Immunochromatography Test Strip. Anal. Chem. 2018, 90, 2134-2140.

(23) Gomez-Martinez, J.; Silvy, M.; Chiaroni, J.; Fournier-Wirth, C.; Roubinet, F.; Bailly, P.; Brès, J.-C. Multiplex Lateral Flow Assay for Rapid Visual Blood Group Genotyping. Anal. Chem. 2018, 90, 75027509.

(24) Liang, X.-L.; Bao, N.; Luo, X.; Ding, S.-N. CdZnTeS quantum dots based electrochemiluminescent image immunoanalysis. Biosens. Bioelectron. 2018, 117, 145-152.

(25) Liu, J.-X.; Ding, S.-N. Monitoring pyrophosphate anions via cobalt(ii)-modulated fluorescence of cadmium sulfide quantum dots. Anal. Methods 2016, 8, 2170-2175.

(26) Zhang, X.; Bao, N.; Luo, X.; Ding, S.-N. Patchy gold coated $\mathrm{Fe} 3 \mathrm{O} 4$ nanospheres with enhanced catalytic activity applied for paperbased bipolar electrode-electrochemiluminescence aptasensors. Biosens. Bioelectron. 2018, 114, 44-51.

(27) Liu, J.-X.; Ding, S.-N. Non-enzymatic amperometric determination of cellular hydrogen peroxide using dendrimer-encapsulated $\mathrm{Pt}$ nanoclusters/carbon nanotubes hybrid composites modified glassy carbon electrode. Sens. Actuators, B 2017, 251, 200-207.

(28) Wang, C.; Hou, F.; Ma, Y. Simultaneous quantitative detection of multiple tumor markers with a rapid and sensitive multicolor quantum dots based immunochromatographic test strip. Biosens. Bioelectron. 2015, 68, 156-162.
(29) Luppa, P. B.; Müller, C.; Schlichtiger, A.; Schlebusch, H. Pointof-care testing (РОCT): Current techniques and future perspectives. TrAC, Trends Anal. Chem. 2011, 30, 887-898.

(30) Zhou, Y.; Pan, F.-G.; Li, Y.-S.; Zhang, Y.-Y.; Zhang, J.-H.; Lu, S.-Y.; Ren, H.-L.; Liu, Z.-S. Colloidal gold probe-based immunochromatographic assay for the rapid detection of brevetoxins in fishery product samples. Biosens. Bioelectron. 2009, 24, 2744-2747.

(31) Mao, X.; Xu, H.; Zeng, Q.; Zeng, L.; Liu, G. Molecular beaconfunctionalized gold nanoparticles as probes in dry-reagent strip biosensor for DNA analysis. Chem. Commun. 2009, 3065-3067.

(32) Laitinen, M. P. A.; Vuento, M.; Dahl, O.; Hvistendahl, G.; Leskelä, M.; Polamo, M.; Homsi, M. N.; Kuske, F. K. H.; Haugg, M.; Trabesinger-Rüf, N.; Weinhold, E. G. Immunochromatographic assay for quantitation of milk progesterone. Acta Chem. Scand. 1996, 50, $141-145$

(33) Xu, Q.; Xu, H.; Gu, H.; Li, J.; Wang, Y.; Wei, M. Development of lateral flow immunoassay system based on superparamagnetic nanobeads as labels for rapid quantitative detection of cardiac troponin I. Mater. Sci. Eng., C 2009, 29, 702-707.

(34) Peck, R. B.; Schweizer, J.; Weigl, B. H.; Somoza, C.; Silver, J.; Sellors, J. W.; Lu, P. S. A Magnetic Immunochromatographic Strip Test for Detection of Human Papillomavirus 16 E6. Clin. Chem. 2006, $52,2170-2172$.

(35) Orlov, A. V.; Znoyko, S. L.; Cherkasov, V. R.; Nikitin, M. P.; Nikitin, P. I. Multiplex Biosensing Based on Highly Sensitive Magnetic Nanolabel Quantification: Rapid Detection of Botulinum Neurotoxins A, B, and E in Liquids. Anal. Chem. 2016, 88, 1041910426.

(36) Corstjens, P.; Zuiderwijk, M.; Brink, A.; Li, S.; Feindt, H.; Niedbala, R. S.; Tanke, H. Use of Up-Converting Phosphor Reporters in Lateral-Flow Assays to Detect Specific Nucleic Acid Sequences: A Rapid, Sensitive DNA Test to Identify Human Papillomavirus Type 16 Infection. Clin. Chem. 2001, 47, 1885.

(37) Corstjens, P. L. A. M.; van Lieshout, L.; Zuiderwijk, M.; Kornelis, D.; Tanke, H. J.; Deelder, A. M.; van Dam, G. J. Upconverting phosphor technology-based lateral flow assay for detection of Schistosoma circulating anodic antigen in serum. J. Clin. Microbiol. 2008, 46, 171-176.

(38) Yang, Q.; Gong, X.; Song, T.; Yang, J.; Zhu, S.; Li, Y.; Cui, Y.; Li, Y.; Zhang, B.; Chang, J. Quantum dot-based immunochromatography test strip for rapid, quantitative and sensitive detection of alpha fetoprotein. Biosens. Bioelectron. 2011, 30, 145-150.

(39) Li, X.; Li, W.; Yang, Q.; Gong, X.; Guo, W.; Dong, C.; Liu, J.; Xuan, L.; Chang, J. Rapid and Quantitative Detection of Prostate Specific Antigen with a Quantum Dot Nanobeads-Based Immunochromatography Test Strip. ACS Appl. Mater. Interfaces 2014, 6, 6406-6414.

(40) Goldman, E. R.; Clapp, A. R.; Anderson, G. P.; Uyeda, H. T.; Mauro, J. M.; Medintz, I. L.; Mattoussi, H. Multiplexed Toxin Analysis Using Four Colors of Quantum Dot Fluororeagents. Anal. Chem. 2004, 76, 684-688.

(41) Khreich, N.; Lamourette, P.; Boutal, H.; Devilliers, K.; Créminon, C.; Volland, H. Detection of Staphylococcus enterotoxin $\mathrm{B}$ using fluorescent immunoliposomes as label for immunochromatographic testing. Anal. Biochem. 2008, 377, 182-188.

(42) Grabolle, M.; Spieles, M.; Lesnyak, V.; Gaponik, N.; Eychmüller, A.; Resch-Genger, U. Determination of the Fluorescence Quantum Yield of Quantum Dots: Suitable Procedures and Achievable Uncertainties. Anal. Chem. 2009, 81, 6285-6294.

(43) Gong, X.; Cai, J.; Zhang, B.; Zhao, Q.; Piao, J.; Peng, W.; Gao, W.; Zhou, D.; Zhao, M.; Chang, J. A review of fluorescent signalbased lateral flow immunochromatographic strips. J. Mater. Chem. B 2017, 5, 5079-5091.

(44) Hou, S.-Y.; Chen, H.-K.; Cheng, H.-C.; Huang, C.-Y. Development of Zeptomole and Attomolar Detection Sensitivity of Biotin-Peptide Using a Dot-Blot GoldNanoparticle Immunoassay. Anal. Chem. 2007, 79, 980-985.

(45) Zou, Z.; Du, D.; Wang, J.; Smith, J. N.; Timchalk, C.; Li, Y.; Lin, Y. Quantum Dot-Based Immunochromatographic Fluorescent 
Biosensor for Biomonitoring Trichloropyridinol, a Biomarker of Exposure to Chlorpyrifos. Anal. Chem. 2010, 82, 5125-5133.

(46) Deng, X.; Wang, C.; Gao, Y.; Li, J.; Wen, W.; Zhang, X.; Wang, $S$. Applying strand displacement amplification to quantum dots-based fluorescent lateral flow assay strips for HIV-DNA detection. Biosens. Bioelectron. 2018, 105, 211-217.

(47) Li, S.-j.; Sheng, W.; Wen, W.; Gu, Y.; Wang, J.-p.; Wang, S. Three kinds of lateral flow immunochromatographic assays based on the use of nanoparticle labels for fluorometric determination of zearalenone. Microchim. Acta 2018, 185, 238.

(48) Zhu, C.; Zhao, G.; Dou, W. Immunochromatographic assay using brightly colored silica nanoparticles as visible label for point-ofcare detection of clenbuterol. Sens. Actuators, B 2018, 266, 392-399.

(49) Beggs, M.; Novotny, M.; Sampedro, S. A self performing chromatographic immunoassay for the qualitative determination of human chorionic gonadotropin hcg in urine and serum. Clin. Chem. 1990, 36, 1084-1085.

(50) Zhao, Y.; Zhang, G.; Liu, Q.; Teng, M.; Yang, J.; Wang, J. Development of a Lateral Flow Colloidal Gold Immunoassay Strip for the Rapid Detection of Enrofloxacin Residues. J. Agric. Food Chem. 2008, 56, 12138-12142.

(51) Gao, X.; Zheng, P.; Kasani, S.; Wu, S.; Yang, F.; Lewis, S.; Nayeem, S.; Engler-Chiurazzi, E. B.; Wigginton, J. G.; Simpkins, J. W.; $\mathrm{Wu}, \mathrm{N}$. Paper-Based Surface-Enhanced Raman Scattering Lateral Flow Strip for Detection of Neuron-Specific Enolase in Blood. Anal. Chem. 2017, 89, 10104-10110.

(52) Parolo, C.; de la Escosura-Muñiz, A.; Merkoçi, A. Enhanced lateral flow immunoassay using gold nanoparticles loaded with enzymes. Biosens. Bioelectron. 2013, 40, 412-416.

(53) Yuan, X.; Fabregat, D.; Yoshimoto, K.; Nagasaki, Y. Development of a high-performance immunolatex based on "soft landing” antibody immobilization mechanism. Colloids Surf., B 2012, 99, 45-52.

(54) Roth, J.; Bendayan, M.; Orci, L. Ultrastructural localization of intracellular antigens by the use of protein A-gold complex. J. Histochem. Cytochem. 1978, 26, 1074-1081.

(55) Anfossi, L.; Calderara, M.; Baggiani, C.; Giovannoli, C.; Arletti, E.; Giraudi, G. Development and application of a quantitative lateral flow immunoassay for fumonisins in maize. Anal. Chim. Acta 2010, 682, 104-109.

(56) Molinelli, A.; Grossalber, K.; Führer, M.; Baumgartner, S.; Sulyok, M.; Krska, R. Development of Qualitative and Semiquantitative Immunoassay-Based Rapid Strip Tests for the Detection of T-2 Toxin in Wheat and Oat. J. Agric. Food Chem. 2008, 56, 25892594.

(57) Molinelli, A.; Grossalber, K.; Krska, R. A rapid lateral flow test for the determination of total type $\mathrm{B}$ fumonisins in maize. Anal. Bioanal. Chem. 2009, 395, 1309-1316.

(58) Kolosova, A. Y.; Sibanda, L.; Dumoulin, F.; Lewis, J.; Duveiller, E.; Van Peteghem, C.; De Saeger, S. Lateral-flow colloidal gold-based immunoassay for the rapid detection of deoxynivalenol with two indicator ranges. Anal. Chim. Acta 2008, 616, 235-244.

(59) Wang, X.; Li, K.; Shi, D.; Jin, X.; Xiong, N.; Peng, F.; Peng, D.; $\mathrm{Bi}, \mathrm{D}$. Development and validation of an immunochromatographic assay for rapid detection of sulfadiazine in eggs and chickens. $J$. Chromatogr. B: Anal. Technol. Biomed. Life Sci. 2007, 847, 289-295.

(60) Frens, G. Controlled Nucleation for the Regulation of the Particle Size in Monodisperse Gold Suspensions. Nature, Phys. Sci. 1973, 241, 20-22.

(61) Zhang, D.; Li, P.; Zhang, Q.; Zhang, W. Ultrasensitive nanogold probe-based immunochromatographic assay for simultaneous detection of total aflatoxins in peanuts. Biosens. Bioelectron. 2011, 26, 2877-2882.

(62) Hua, X.; Qian, G.; Yang, J.; Hu, B.; Fan, J.; Qin, N.; Li, G.; Wang, Y.; Liu, F. Development of an immunochromatographic assay for the rapid detection of chlorpyrifos-methyl in water samples. Biosens. Bioelectron. 2010, 26, 189-194.

(63) Wen-de, W.; Min, L.; Ming, C.; Li-ping, L.; Rui, W.; Hai-lan, C.; Fu-Yan, C.; Qiang, M.; Wan-wen, L.; Han-zhong, C. Development of a colloidal gold immunochromatographic strip for rapid detection of Streptococcus agalactiae in tilapia. Biosens. Bioelectron. 2017, 91, $66-69$.

(64) Shao, Y.; Duan, H.; Guo, L.; Leng, Y.; Lai, W.; Xiong, Y. Quantum dot nanobead-based multiplexed immunochromatographic assay for simultaneous detection of aflatoxin B1 and zearalenone. Anal. Chim. Acta 2018, 1025, 163-171. 